\title{
'I like to go out to be energised by different people': An exploratory analysis of mobility and wellbeing in later life
}

\author{
FRIEDERIKE ZIEGLER \\ Institute for Life Course Studies \\ Keele University \\ Staffordshire ST5 5BG \\ United Kingdom \\ Email: f.ziegler@ilcs.keele.ac.uk

\section{TIM SCHWANEN} \\ Transport Studies Unit \\ School of Geography and the Environment \\ University of Oxford \\ Oxford OX1 3QY \\ United Kingdom \\ Email: tim.schwanen@ouce.ox.ac.uk
}

\section{Ageing \& Society}

Final version

May 2010 


\title{
'I like to go out to be energised by different people': An exploratory analysis of mobility and wellbeing in later life
}

\begin{abstract}
This paper adds to the growing number of studies about mobility and wellbeing in later life. It proposes a broader understanding of mobility than movement through physical space. Drawing on the 'mobility turn' in the social sciences, we conceptualise mobility as the overcoming of any type of distance between a here and a there, which can be situated in physical, electronic, social, psychological or other kinds of space. Using qualitative data from 120 older people in County Durham, England, we suggest that mobility and wellbeing influence each other in many different ways. Our analysis extends previous research in various ways. First, it shows that mobility of the self - a mental disposition of openness and willingness to connect with the world - is a crucial driver of the relation between mobility and wellbeing. Second, while loss of mobility as physical movement can and often does affect older people's sense of wellbeing adversely, this is not necessarily so; other mobilities can at least to some extent compensate for the loss of mobility in physical space. Finally, wellbeing is also enhanced through mobility as movement in physical space because the latter enables independence or subjectively experienced autonomy, as well as inter-dependence in the sense of relatively equal and reciprocal social relations with other people.
\end{abstract}

Key words: mobilities, wellbeing, qualitative methods, Durham (UK) 


\section{Introduction}

There is growing attention to older people's everyday mobility outside the home among scholars from various backgrounds including gerontology, transport studies, health research and urban studies (e.g. Marottoli et al. 1997; Banister and Bowling 2004; Mollenkopf et al. 2005; Siren and Hakamies-Blomqvist 2009; Spinney, Scott and Newbold 2009). Several factors are responsible for this increased interest. One is the recent and projected increase in the number of older people in most Western societies, and their own desire to lead independent lives, which presupposes a minimum capacity to move around within and outside their homes. Another is that out-of-home mobility is widely believed and has been shown to be positively correlated to wellbeing in old age (e.g. Marottoli et al. 1997; Spinney, Scott and Newbold 2009). The widespread attention to this relationship in academic and policy-oriented documents is embedded in the discourse around successful, healthy and active ageing (World Health Organization 2002; Department of Health 2005; Lowe and Speakman 2006). Attention to the relationships between out-of-home mobility and wellbeing by social gerontologists is nothing new (e.g. Cutler 1972; Carp 1988), but nonetheless some have recently argued that the associations are complex and only partially understood. For instance, Banister and Bowling (2004) suggested that mobility needs to be conceived broadly if we are to understand how it contributes to wellbeing in old age: 'the standard transport representations in terms of trips made, travel distance and transport mode only represent part of the picture' (p. 11). More recently, Siren and Hakamies-Blomqvist (2009) argued that a thorough understanding of the concepts of mobility and wellbeing and their interrelationships is missing. 
Against this background, the present article addresses three objectives. First, we critically review the conceptualisations of mobility and wellbeing and their inter-relations in the gerontology, transport and related literatures. Second, drawing on work known as 'the mobility turn' in the social sciences (Sheller and Urry 2006), we propose a broad conceptualisation of mobility that refers not only to movement in physical space but also to overcoming separation in electronic, social and psychological spaces. Third, we examine some of the pathways of influence through which mobility and wellbeing in later life are inter-related. To this end, we draw on focus groups and in-depth interviews with 120 independently-living men and women aged 60-95 years in County Durham in North East England. The remainder of this paper begins with an examination of mobility as a concept, partly through a review of previous understandings in the academic literature, which leads to our proposal for a more holistic alternative. We then focus on wellbeing, summarising existing conceptualisations and reviewing the evidence about its associations with mobility. The third part gives more information about the empirical study and the analysis of the data, and discusses the results in two steps; the first reviews the empirical support for our conceptualisation of mobility, and the second outlines ways in which mobility and wellbeing were inter-related for the study participants.

\section{Mobility: review and re-conceptualisation}

Concepts of mobility in gerontology, transport and health studies

Mobility is intricately linked to movement. While movement can occur in different types of space (including social, psychological and electronic space), it is understood in the academic literature about ageing as undertaken primarily in physical space. Three understandings of 
mobility-as-movement are prominent in gerontology, transport studies and health research. First, many studies focus on mobility as actually realised movement. It is very common to measure mobility in terms of the daily or weekly number of trips that people make, the distances they cover and the transport modes they use (e.g. Waldorf 2003; Föbker and Grotz 2006; Paez et al. 2007). Some researchers, particularly in transport studies, have also considered mobility as a spatio-temporal phenomenon and analysed the timing of trips, their duration or their links with activity participation at the destinations (e.g. Hanson 1977; Hildebrand 2003; Scott et al. 2009). Second, mobility is also understood as the potential for movement. Some studies consider the possibilities or options people have for movement. Mollenkopf et al. (2004, 2005), for instance, considered the options older people have for using different transport modes as an indication of older people's freedom, autonomy and flexibility, and Ieda and Muraki (1999) concentrated on the possession of a driver's licence and the number of cars and bikes owned. Other authors measure the potential for moving in terms of unfulfilled activity wishes or satisfaction with the out-of-home activity participation (Siren and Hakamies-Blomqvist 2006; Scheiner 2006). The reasoning is that mobility is not fully secured if older people have unfulfilled activity wishes or are dissatisfied with their outof-home activities.

Third, mobility is also understood in terms of physical functioning (e.g. Schaie and Pietrucha 2000; Gabriel and Bowling 2004; Davey 2007). Geriatricians have for long examined physical functioning through quantitative measures of people's difficulties in undertaking the basic activities of daily living (ADLs) or the instrumental activities of daily living (IADLs), in part to assess older people's need for care or assistance for independent living (e.g. Lawton and Brody 1969; Katz 1983). There are many measures of ADLs and IADLs and they are composed of differing items but the assessment of 'movement through physical space' is 
often included. Lawton and Brody's (1969) physical self-maintenance scale evaluates ADLs and includes an item about 'physical ambulation' (i.e. whether people can go about the city, only within the block or the dwelling, or need some form of assistance). In relation to mobility, their influential IADL scale includes an assessment of a person's ability to shop independently and of their independent capabilities regarding the use of public transport or driving a car. Other scales use similar items; for instance, Mor and colleagues' (1989) focuses on (changes in) older people's ability to climb independently 10 stairs, walk a quarter-of-a-mile (402 metres), carry $25 \mathrm{lb}(11.3 \mathrm{~kg}$ ) or do heavy housework. Ayis et al. (2007) analysed seven ADLs, including walking at least 400 yards (366 metres), getting on a bus, going up and down stairs, going shopping and carrying heavy bags.

The three outlined understandings of mobility have several shared features. First, they are instrumental in character. There is a strong focus on movement from A to B, and at least in the transport literature a journey or trip is seen as a 'derived demand', derived from the need to participate in activities at the destination that are seen as conceptually distinct from the movements to access them (Mokhtarian and Salomon 2001; Urry 2006). Second, there is a strong focus on trips to access daily activities, such as buying groceries or meeting others. Less frequent travel purposes, as for holidays or family visits, many of which cover longer distances and involve overnight stays, tend not to be considered, although they may have a strong influence on older people's wellbeing. Third, attention to how older people experience movement is rather limited. Studies of physical functioning measure older people's cognitive assessment of difficulties in moving through space, but do not include the involved emotions or the meanings people ascribe to these movements. 
In contrast to the above functional conceptualisations of mobility, Mollenkopf et al. (2004, 2005) have challenged the conceptual distinction between trips and activities. They include the diversity of leisure activities as one dimension of mobility in their empirical work (alongside trip frequency and the transport options that people have), and thus qualify the instrumental character of the mobility concept. Transport researchers Alsnih and Hensher (2003) argued that a definition of mobility should recognise one or more of the five dimensions: access to destinations; the psychological benefits of travel, including a sense of independence; the benefits of physical movement; maintaining social networks, and potential travel. This conceptualisation is clearly broader than in most other studies. Nonetheless, they focus on one transport mode (car use) and trip frequency in the remainder of the paper (partly because they review previous work). In a similar vein, Metz (2000) considered mobility in later life to encompass five elements: travel to achieve access to desired people and places; potential travel; the psychological benefits of movement; exercise benefits; and involvement in the local community. Metz considered the various benefits derived from (potential) movement to be intrinsic to mobility. Finally, some studies have explored the emotions involved in and meanings ascribed to mobility in later life, with many focusing on the perceived benefits of driving a car or the effects of driving cessation (e.g. Siren and Hakamies-Blomqvist 2005; Davey 2007).

Nonetheless, the instrumental perspective - movement from A to B in physical space dominates the scientific literature about older people's mobility. As Kaiser (2009: 413) observed, the Latin source of the word mobility, mobilitas, has '[from] its beginning ... been used in psychological, social and even allegorical ways'. Adopting a broader conceptualisation may help us understand better how wellbeing and mobility are connected in later life. The question, then, is how mobility can be re-conceptualised. We believe that 
recent work in the social sciences, known as the 'mobility turn' or 'new mobility paradigm' offers useful building blocks in this regard.

The 'mobility turn' in social and cultural theory

According to Sheller and Urry (2006), cultural sociologists and cultural geographers have long tended to examine social life without due recognition of the crucial role of the systematic movements of people for work and family life, for leisure and pleasure, or for politics and protest. Insofar as cultural sociologists and cultural geographers have considered travel, they have tended to view it as 'a black box, a neutral set of technologies and processes' (Sheller and Urry 2006: 208). In recent years, however, they have begun to theorise and empirically examine the mobility, and immobility, of people, objects, information and ideas. Part and parcel of this mobility turn is a critical analysis of the term mobility.

For instance, Urry (2007) distinguished five interdependent mobilities as key to social life. These include the corporeal travel of people in all its varieties (including daily trips, holiday travel and migration); the physical movement of objects to producers, consumers and retailers; the imaginative travel enacted by images of people and places in photos, books, TV and other media; the virtual travel enabled by the Internet; and the communicative travel trough person-to-person messages by letters, telephones and other technologies. Urry's work highlights the social consequences of mobilities: they afford social relations to people and places that are physically distant and that may enhance wellbeing. While Urry's typology considers physical and electronic movement, it does not address movement in social, psychological, conceptual or imaginative spaces. This type of mobility is termed 
'metaphorical movement'. Frello (2008: 32), for instance, defines mobility as 'a relational concept characterized by the overcoming of physical, psychological, or other types of distance, or by the transgression of a state or condition'. She considers mobility as the transgression of difference or distinction, such as between 'here' and 'there', 'me' and 'others' or between different imaginary worlds. Here the notion of 'distance' refers not only to the conventional metric system or physical spaces, but rather the distinction between 'near' and 'far away' relates to the quality or character of the relationship between the entities involved. Hence, engagement in a relationship with the unknown in physical, social or metaphorical spaces can be considered an act of movement, expressed for instance as an open and inviting attitude towards people who are 'different' (in terms of age, gender and race/ethnicity), or an inclination towards inter-disciplinary scientific research. In this paper we label this engagement with the unknown as 'mobility of the self': a will or psychological disposition to connect with the world and otherness, with people and places beyond oneself, one's household or one's residence.

\section{Wellbeing: review and links with mobility}

\section{Definition and constituents of wellbeing}

Scholarly thinking about 'the good life' dates back at least to the ancient Greeks (George 2000), but wellbeing has attracted growing academic attention in recent decades.

Contributions to the debates around wellbeing have come from a wide range of disciplines, from gerontology and health studies to psychology, economics and human geography (George 1981, 2000; Diener et al. 1999; Ryan and Deci 2001; Kahn and Juster 2002; Bowling 2005; Kahneman and Krueger 2006; Carlisle and Hanlon 2007; Fleuret and 
Atkinson 2007). The disciplinary diversification of interest in wellbeing has exacerbated the problems of defining what was already an elusive concept. As a first approximation, we can say that wellbeing has been considered both an objective phenomenon related to people's living conditions (e.g. level of income, neighbourhood type, housing situation) and a subjective phenomenon that describes an individual's experience of how well she is or lives (e.g. Kahn and Juster 2002; Fleuret and Atkinson 2007). One influential perspective of wellbeing as a subjective phenomenon focuses on subjective wellbeing (SWB). George (1980: 359) defined subjective wellbeing as 'subjective perceptions of life quality' and argued that it comprises at least life satisfaction and happiness as lower-level concepts. Life satisfaction refers to people's relatively long-term cognitive assessment of life quality; happiness to short-term, affective judgments of wellbeing.

Work on SWB has been criticised, however, for being atheoretical and incomplete. Many criticisms stem from the psychological wellbeing (PWB) tradition, which conceives of perceived wellbeing in terms of human development and existential challenges of life. The most well-known representative of this approach is probably Carol Ryff, whose theoretically grounded model of PWB has six dimensions: autonomy, environmental mastery, personal growth, positive relations with others, purpose in life and self-acceptance (Ryff 1989a, 1995). Research indicates that SWB and PWB are only partially overlapping constructs, and that the more existential aspects of PWB are not captured by SWB measures (Keyes, Shmotkin and Ryff 2002).

Partly related to the PWB literature, another research tradition focuses on lay conceptions older people's own understandings - of perceived wellbeing and quality of life (e.g. Ryff $1989 b$; Bowling 2005). A feature of this approach is its holistic character, in that it is 
grounded in the complexity of older people's everyday experiences. The resulting conceptualisations of wellbeing cross the boundaries between academic disciplines or traditions and unite the physical, psychological and social realms of wellbeing and the self (Bowling 2005). A review by Gilroy $(2007,2008)$ showed that UK studies following the lay approach produced consistent results despite considerable diversity in methods, objectives and study populations: good health, sufficient income to participate in society, a strong social network, the capacity to make a contribution to the community or society, a secure home and the ability to access information and activities all contribute to perceived wellbeing in old age. Gilroy also pointed out that a supportive neighbourhood with good access to local shops, facilities for older people and transport and 'the ability to get out and about' promoted wellbeing in old age (2008: 149). These aspects of wellbeing, Gilroy suggested (2007: 346), essentially enable independence, a key component of wellbeing in later life. Other studies not reviewed by Gilroy confirm the above (e.g. Wilhelmson et al. 2005; Bowling and Gabriel 2007) and emphasise the importance of mental factors to wellbeing, such as a positive outlook on life and the acceptance of circumstances that cannot be changed (e.g. Ryff 1989b; Gabriel and Bowling 2004).

Wellbeing and mobility

Many studies have verified that mobility, defined as actual or potential movement in physical space, enhances quality of life or wellbeing in later life. Quantitative research has repeatedly found positive statistical associations between indicators of trip-making, out-of-home activity engagement, the availability of various means of transport and unfulfilled transport needs on the one hand and measures of wellbeing on the other (e.g. Cutler 1972; Ieda and Muraki 1999; Cvitkovich and Wister 2001; Banister and Bowling 2004; Mollenkopf et al. 2005; 
Spinney, Scott and Newbold 2009). However, many quantitative studies focus on establishing statistical correlations and fail to decipher the mechanisms that link mobility to wellbeing. An exception is a study by Cvitkovich and Wister (2001), which drew on person-environment fit theory to show that elders who experience difficulty with driving or using public transport prioritise environmental needs and actively adjust mobility expectations in order to sustain wellbeing.

Other studies suggest some of the pathways of influence which link physical mobility and wellbeing. Firstly, movement in physical space allows people to meet others and go to places and so helps to fulfil basic, social and emotional needs (e.g. Carp 1988; Metz 2000). Secondly, several authors have indicated that changes in people's health, such as physical illness, limits people's mobility outside the house and so reduces contact with friends, relatives and neighbours and the wider (local) community, which may cause or aggravate isolation, loneliness and depression (e.g. Smith et al. 2002; Mollenkopf et al. 2004; Allen 2008). Thirdly, many studies have addressed issues concerning the effects of driving cessation, suggesting that older people who have to give up driving tend to engage less in activities outside the home and especially in 'discretionary' activities such as visiting friends or enjoying nature (e.g. Harrison and Ragland 2003; Marottoli et al. 2000; Davey 2007). People's lifestyle and positive identity are frequently affected as a result. Former drivers can feel a profound loss of independence, especially if they live in car-dependent regions or use the car as compensation for deteriorating functional health (Adler and Rottunda 2006; Davey 2007; Siren and Hakamies-Blomqvist 2009). Also, older people who stop driving are subsequently more likely to develop depressive symptoms and related health problems (Marottoli et al. 1997; Ragland, Satarianano and MacLoad 2005; Windsor et al. 2007). In summary, we note that the existing literature on mobility and wellbeing issues conceives mobility as actual and potential movement through physical space. Much of the discussion 
focuses on restrictions to mobility and the potentially negative consequences for wellbeing as people grow older.

\section{The research design}

The setting and sample

Our qualitative study was carried out in three of the western, rural district councils of County Durham in the North East of England over 10 months during 2005-06. The rurality of the area has an impact on the mobility of older people, in that many facilities and services are distant and difficult to access, so transport mobility is a particular concern. The study covered participants from at least five settlements in each of the three districts (15 groups in all). The settlements varied from small towns with adequate facilities, to very remote villages without any facilities (such as post offices, shops or GP surgeries) and infrequent bus services.

The research included 119 participants for the focus groups in the 15 locations. In addition, nine interviews were carried out across the study area. A convenience sampling approach was used to recruit community-dwelling men and women aged 60 or more years. The participants were chosen from a larger group of interested volunteers using selection criteria such as the age distribution and gender ratios of the population across the three districts. In addition, participants were selected according to mobility-related criteria. These were based on a simple questionnaire which asked participants about self-rated presence or absence of a physical condition which limits how individuals get around, living arrangements, access to a car within the household and receipt of regular help and assistance with everyday tasks. A cross-section of men and women of varying ages and that were living in diverse 
circumstances was selected. Among the 119 who were aged 60-95 years, 71 per cent were women and 29 per cent men (compared to $55 \%$ and $45 \%$ respectively in the general population of County Durham).

\section{Methods}

The focus groups were held in 15 community centres and village halls, two in each location. This paper uses the transcripts of the first round of focus groups in each location which discussed mobility-related issues. These focus groups had from two to 12 participants and sought to elicit the participants' views and experiences regarding the intersections between spatial mobility, ageing and wellbeing. The discussions were based on mental maps and on participatory diagramming, which is a research tool whereby participants respond to research questions by drawing diagrams and analysing these collectively (Kesby, 2000). Out of these discussions emerged a breadth of data which included contrasting or common experiences and attitudes with regard to mobility, ageing and wellbeing. The conversations during the diagramming and mapping exercises and discussions were audio-recorded and subsequently transcribed.

Nine semi-structured interviews were carried out with four women and five men aged 73 to 90 years who had special mobility requirements because of sensory impairments or physical or mental disabilities. The interviewees were selected to represent the two genders and different impairments. The sometimes multiple conditions experienced by interviewees included: hearing impairment and senility, blindness, arthritis, dementia, multiple sclerosis, and chronic obstructive pulmonary disorders (COPD). Through the use of a life-history approach, the interviews allowed for a deeper exploration of the themes which had been 
raised in the focus groups. In addition, because of the participants' particular impairments, they also enabled a deeper understanding of issues regarding mobility and wellbeing that less able-bodied individuals have to cope with on a day-to-day basis. Like the focus groups, the interviews were audio-recorded and transcribed.

\section{Data analysis}

The qualitative data analysis in this participatory project was underpinned by a constructivist grounded theory approach. The data analysis combined elements of phenomenological with discursive or structural analysis. This constructivist approach is well suited to this qualitative research project because it allowed us to tell a story about people, their situation and experiences, as well as taking into consideration wider social processes and power relations. The first author carried out the initial open and axial coding, which moved from very broad themes, such as mobility and well-being, to the gradual emergence of lower-level sub-themes or dimensions and to the relationships between themes and sub-themes. It was at this stage, for instance, that she proposed to identify physical health, independence, mental health and emotional wellbeing, social relations, and continuity of the self and self-identity as constituents of wellbeing. The emergent scheme of themes, subthemes and their interrelationships as well as relevant sections of transcripts were then discussed with and validated by the second author. Minor differences in interpretation between the authors were resolved in a series of discussions and exchanges, which led to refinements in the structure of themes, dimensions and interrelations. In those discussions and exchanges, the scheme was also put into dialogue with the literature reviewed above, which resulted in further development of the analytical categories. In the following section we discuss (a part of) the scheme of themes, sub-themes and interrelationships on the basis of quotes selected from the 
focus groups as representative of the participants' views and because they clearly illustrated the themes, sub-themes and interrelationships.

\section{Results}

\section{Mobilities}

The analysis of the focus group conversations revealed two aspects of how older people experience and understand mobility that qualify the emphasis on the instrumental character of mobility in the prevailing scientific conceptualisations. The first is that older people's understandings of mobility vary relative to, and depend on, their embodied experiences and circumstances. The focus group discussions suggest that, with ageing, people tend to develop an increased awareness of their own restrictions to movements in physical space, as the words of Richard, aged 69 years, imply:

I don't think I have the energy and I think that some immobility comes with age. You know, I mean I have problems with stairs. I know exactly how to deal with it as far as I can, but in addition to that, you're just not as strong, you're not as fit as you used to be, you can't be, can you? ... No, exactly, you haven't got the balance. There's nothing wrong with me, but steps become formidable and nothing will get me up a ladder now, I'll be quite honest you know [emphasis added].

Our data were collected at a single point in time and are not longitudinal, but nonetheless suggest that older people's understandings and experiences of mobility change as they age: the focus group participants noted and commented on these changes in themselves over time. The participants' perceptions of change are exemplified by the italicised words in Richard's account. Thus, understandings of mobility in old age are dynamic. 
The second aspect of older people's own understanding of mobility that we wish to emphasise is its interwoven character. This aspect came to the fore during the analysis and interpretation of the data which is partly based on our knowledge of the mobility turn literature. It was articulated explicitly once by one participant in a focus group discussion who remarked, 'It's all connected, isn't it?' In this case, the discussion linked mobility with the participants' dread of encountering 'gangs' of young people in the street. Two forms of 'interwovenness' warrant discussion. First, as illustrated above, the participants’ understandings of mobility in physical space did not coincide clearly with the taken-forgranted conceptual distinction in transport research between trips to access destinations and activities undertaken at destinations (Mokhtarian and Salomon 2001; Urry 2006). It seems, therefore, that movement in physical space is less instrumental and less 'a derived demand' to participants than it is in the conceptualisations of transport researchers. Participants speak about 'being outside' and 'keep going' (Jane and Nancy, more details below), about 'going to the theatre' (Doreen, also below) and exchanges with others while walking on the street (David, also below). We will use the term 'mobility practices' to denote all the bundles of acts involved in movement through physical space and undertaken during movements or at stationary locations in the remainder of this article. Second, the analysis made clear that movement in physical space is intimately related to what we have termed 'mobility of the self' and to positive attitudes towards certain behaviours. These links become clear from the conversation between Jane (73 years) and Nancy (67 years):

Jane: I'm generally you know, involved in a lot of things really, simply because it keeps me active and I could, I suppose just sit at home and vegetate, but I don't want to do that. I want to keep going as long as ever I can. I have a garden at the front of the house and I do that myself, which I enjoy when the weather is fine. I like being outside and [this village] is a lovely place to live, so I consider myself extremely fortunate because I have a lot of very good friends and neighbours who are very kind to me, ... so I have a lot to be thankful for.

Nancy: But as I've said before it's what we make it. 
Jane: Exactly, we could just go in and shut the door and that would be it, but we don't do that, we try to be outgoing.

As Nancy pointed out, it is the individual's determination and motivation actively to engage with the world that is crucial for keeping the older person socially active and physically mobile. Mobility practices such as 'going out' result from the individual's efforts to be an 'outgoing' person and from her positive attitudes towards concrete acts and behaviours (e.g. enjoying gardening). We may thus infer that mobility in physical space and in psychological space go hand-in-hand. This suggestion is reinforced in David's (60 years) description of the contrast between his wife's and his personalities:

She's very shy, my wife, very shy and if I don't go somewhere she won't. Where I'm not bothered, I'm a bit like [fellow participant], we're quite outgoing people and I would come to allsorts on my own. Just enjoy myself. There's always someone to talk to. That's the good thing about [this village], the people are very, very friendly and if you come to a social function here there's always somebody will come and talk to you if you're on your own. Or even the street, you can't walk past someone in the street, they'll pass comments.

David's openness to engagement with the physical and social environments around him supports his mobility practices. His other contributions to the group discussions reveal that he kept fit by running, was engaged with the parish council and involved in running the village hall. If movement in physical space and mobility of the self reinforce each other, the converse is also true. For Joan (74 years), for instance, a heightened consciousness of her physical mobility restrictions had undermined her confidence in and willingness to engage with the social world of her community, which consequently had affected both her mobility practices and her attitudes:

A person with arthritic hands couldn't pick a pair of scissors up because you go for your scissors and they don't work. You can't comb your hair. When you go to the toilet, you have great difficulty even pulling your pants up, you know. It undermines your confidence. ... I find now that I'm starting to get 
a bit reclusive. I've never ever been in the village in my wheel chair ... and it's a lovely little village but the reason I don't go down the village in the wheel chair is [because] people are so kind and they say, 'What's the matter Joan?' You know: 'What's happened?' And I just don't want to sort of give them all a sob story. ... I just wouldn't like to go down in the village in a wheelchair. Plus the fact, you see, to get in and out of these shops, it's all steps, and the shops in [the village] are so tiny that you couldn't get round and you don't want to make yourself a nuisance. So, no, I don't go down the village.

As a result of her reduced open-mindedness, her fear of social interaction and wish to avoid others' pity, and changes in her attitudes, Joan's mobility practices had become more restricted than warranted by the arthritic condition, but mutual reinforcement is not the only way in which physical and mental mobilities relate to each other. As suggested by the quotes from Hilda (65 years) and her husband Gerald, who was 67-years-old and wheelchair bound, the mobility of the self and positive attitudes can to some extent replace movement in physical space as a basis for the older person's engagement with the world:

Gerald: I got a cancerous tumour took off the spine and consequently my legs have gone, but they're getting a bit better, slowly but surely. All alike really, once you get to a certain age and you're immobile, that's it really; that's our life.

Hilda: As I say, mobility doesn't affect me in any shape or form. I'm quite alright really. It didn't occur to me at all really. I have a happy life. I'm quite cheerful. We've plenty of friends come to the house. We've got loads of company. We're not lonely, and we're interested in all affairs: politics, everything. Our minds are active, and we complain and we keep our minds active to see what's going on in the world. As far as we can, we enjoy life and make the most of it.

In responding to the question, 'What does mobility mean to you?' Gerald emphasised his physical 'immobility' and the restrictive effect this had on his life. In contrast, his wife talked much more positively about the couple's general engagement with the world. In her attempt to maintain a positive attitude toward life in spite of her husband's disability, Hilda's interpretation of personal mobility had shifted from a purely physical concept to one focused 
on social and psychological engagement. Based on the discussions with Hilda and other participants, we propose that mobility in later life should be understood holistically and relationally along the lines proposed by Frello (2008); that is, mobility is the overcoming of difference and distinction between 'here' and 'there' in physical, mental and other kinds of space. We consider this relational conception of mobility useful as it opens up several opportunities for understanding the complex connections between wellbeing and mobility. It is to these that we now turn.

\section{Wellbeing}

As described earlier, five dimensions or constituents of wellbeing emerged during the data analysis: physical health, independence, mental health and emotional wellbeing, social relations, and continuity of the self and self-identity. These constituents are in many ways related with each other as well with mobility in physical and mental space. The complexity of the inter-relationships was aptly illustrated by Doreen (62 years):

I like going to the theatre and I just generally like coffee mornings, being with people ... but I live on my own out of choice because when I see people a lot I can go home and shut the door and say, 'Go away'. So I've got my life nicely balanced. ... I think travelling would be a worry for me if I didn't have the car and was old and infirm because I like to go out to be energised by different people. So I need to have that input in my life and if I didn't get out and about I'd be stuck.

Her life was characterised by a balance between social contact outside the house and solitude at home and by the ability to choose when to interact with others. Socialising was thus an important aspect of wellbeing, which motivated Doreen - and David and Nancy and Jane and many other interviewees - to go out. Making a universal generalisation from one person will not impress. And mobility practices outside the house - the theatre for Doreen or the village and the street for David - afforded this socialising and sense of wellbeing. Mobility practices 
are thus both an expression of an individuals' will to connect with the world and an enabler for interactions with other people and places, which Doreen described as 'energising'. We can identify a continuous, self-reinforcing cyclical loop: her disposition of openness to other people and positive attitudes made social contact possible using mobility practices, and from this social contact Doreen (and others) derived emotional wellbeing which reinforced her disposition of openness (i.e. being 'outgoing') and motivation to go out.

In the quote above, Doreen also expressed her dependence on a car for maintaining her active and independent lifestyle. It allowed her to travel with relative ease and convenience, and importantly it meant that she did not have to rely on others. The importance of the private car was also evident for Jim (aged 84 years):

Jim: I find it very frustrating, my lack of mobility. I live 100 yards at most from this hall and it will take me nearly half-an-hour to walk and that's why I use the car. I use it as another pair of legs. ... I'm hoping I can go to the Black Forest again this year. When my wife was alive we used to go two or three times every year without fail. ...Oh yes, I like to do what I want to do when I want to do it.

FZ: The car enables you to remain independent?

Jim: Oh yes, in fact almost totally independent. ... But I like my visits. I visit the homes and the hospitals and sick people who I know. I'll go into their rooms or into their houses, but if I don't know them, I'll stand outside. ... My wife used to and I ... I like doing it. People say: 'Oh I couldn't be bothered', and I say, 'Well, I can because it helps me as much as it helps the people I am going to see'.

This exchange draws attention to two points. First, the car and the spatial mobility that it gives Jim contributed to his wellbeing in multiple ways. Not only did it enable his community activities and through those his social relationships, it also provided continuity with his past and a link to his deceased wife, and thereby supported his sense of self. The use of the car compensated for Jim's declining physical health. Second, Jim's remarks suggest that independence mediates the links between mobility and wellbeing. Independence seems to be 
understood by Jim primarily in terms of autonomy in carrying out ADLs and freedom of choice but he also acknowledged the benefits of his visits to others and to himself and thus a degree of inter-dependence.

\section{[Table 1 about here]}

While mobility can support wellbeing and vice versa, the two can also regress together in a downward spiral. We will examine two examples. Joan's (aged 74 years) arthritic condition and mobility have been discussed previously. Her words show how restrictions on physical movement have had multiple negative impacts on her self-confidence, self-efficacy and mental health. As a consequence of her restrictions, Joan had become disconnected from other people. For Joan, social encounters were fraught with fear instead of being a resource for coping; they threatened her identity as an independent and self-reliant individual by making her conscious of her disability. The maintenance of this independent identity had taken on an important role for Joan in sustaining a positive self-image and attitude towards life. Table 1 describes Joan's downward spiral in more detail. The second example is Robert (aged 75 years). As revealed by the following exchanges between Robert, his wife Mary, and his daughter, Julia, he considered that the changes in his mobility were the result of a medical condition related to the ageing process, and that these had significant repercussions for his emotional wellbeing and continuity of the self:

Robert: I've just had a medical condition [diagnosed] and the medicine that I've taken has deprived me of my driving licence and it is the most shattering blow I've ever felt in my life ... There's no return and I've found it very difficult to come to terms with. One of the penalties of living and I wouldn't wish it on any of you to have that trauma. ... My wife, she is a similar age to me and I haven't helped to carry luggage up the bank [slope] to where we live and things like that; it's very inconvenient.

Julia: But it's hard having to ask [others for help], isn't it?

Mary: Well, [it is] when you've always done it yourself. 
Robert: Really quite humiliating, you know. ... I've never been as old as this before.

The exchanges show that Robert's identity as an individual and a husband were closely linked with his ability to provide lifts in the car. He found the loss of his driving licence and his independence as 'humiliating', and felt unable to go out at all, imprisoned in his home and useless to his wife, not being able to help her carry goods and luggage home. Robert was going through a grieving process for this loss of a specific mobility practice which enabled independence, and his anger and sadness were part of this process. He suddenly had to come to terms with the bodily ageing process which may involve a re-assessment of his own identity and his social relationships and social roles.

While Joan's and Robert's cases suggest that severe limitations on movement through physical space significantly reduce wellbeing in later life, this is not inevitably so. Earlier we saw that some participants, including Jim, used the car as a mobility aid and a compensation tool to sustain mobilities and wellbeing (Jim). There are, however, also other possibilities for maintaining wellbeing in spite of declining physical functioning. Hilda, whose situation has been discussed above, was keen to stress that she and her husband were cheerful and that the couple remained in touch with the world in spite of several restrictions on his physical mobility. Hilda's wellbeing was related to her mobility of the self, i.e. her openness, and was maintained through social-support networks with people who came to the house. Barbara (73 years) also exemplified the role of mobility of the self in maintaining a degree of well-being. She cared for her husband who had multiple sclerosis and had become wheelchair-bound and unable to move without assistance. Her positive attitude supported the couple's emotional health and wellbeing. As Barbara said: 
Positive thinking, that's what we do. ... So we don't allow any depression or anything, do we? I try and keep a cheerful house; and flowers and just nice, do you know, nice things.

Barbara's positive attitude enabled the couple to maintain some independent physical mobility. The interview data reveals that it was as a result of her continuous campaigning that dropped curb stones were installed by the council around their neighbourhood, and that these enabled her husband to venture outside in his wheelchair and to attend the weekly lunch club in the village hall.

\section{Discussion and conclusions}

Based on the literature associated with the mobility turn in social and cultural theory and our analysis of focus groups and interviews from County Durham, we have suggested that mobility in later life is more than a means of accessing people and places in distant space, and more than a mere function of or resource for undertaking the activities of daily living. Mobility is also relational: one aspect of mobility as a multidimensional concept is the willingness to engage mentally and socially with 'difference', to develop and maintain relations with other people and affairs, both at the level of the local community and more widely. Further, we have proposed that mobility changes over time. While further (qualitative) research adopting a longitudinal approach to data collection is warranted, the focus group discussions in County Durham suggest that individuals' understandings of mobility and mobility practices are redefined as their body ages and physical capabilities can no longer be taken for granted. In an attempt to integrate the literature from the mobility turn with the results from the data analysis, our interpretations have engaged dialectically with the work of Urry (2007) and Frello (2008). In this way, we have been able to construct a typology of salient dimensions of the mobility in later life, as presented in Table 2. We argue 
that a full understanding of personal mobility requires close attention to mobility practices, the mobility of the self (of identity rather than the body), a person's attitudes towards mobility practices, imagined mobility, and electronic mobility.

\section{[Table 2 about here]}

We have been unable to include all dimensions in the discussion of the empirical analysis in this paper, but the complete set of dimensions is set out here because they feature prominently in the work of mobilities researchers (e.g. Urry 2007; Frello 2008). We have attempted to show that these dimensions are related to wellbeing in later life and suggest that future research may contribute to further unravelling the interdependences of these dimensions and their connections to wellbeing. Our own empirical analysis has shown that mobilities and wellbeing are connected in diverse and complex ways. Many pathways of influence can be identified, and Table 2 offers one way to think about these. The table emerged from iterative analysis of the transcripts of the focus groups and interviews and generalises some of the findings that have been discussed above via specific quotes. We include it here as a heuristic device, intended to stimulate further thinking about ways in which mobility and wellbeing are interrelated.

\section{[Table 3 about here]}

Our empirical analysis complements the existing literature about mobility and wellbeing in various ways. For instance, mobility practices allow older people to meet others and so to fulfil social roles and maintain mental and emotional wellbeing (cf. Carp 1988; Metz 2000). This became most clear in the self-reinforcing loop that we identified between mobility of the self, mobility practices and mental and emotional wellbeing. This was exemplified by the quote from Doreen. Our study extends previous research in suggesting the crucial role played by a willingness to connect with the world, which is the driving force of the loop. The 
empirical analysis has also shown the effect that reduced physical health and restricted movements outside the home can have on a reduction of social contacts and on a deterioration of mental health and emotional wellbeing ( $c f$. Smith et al. 2002; Mollenkopf et al. 2004; Allen 2008). This pathway was exemplified by Jean and Robert. In both cases, however, we saw that continuity of self-identity was also affected. Given that our study has been exploratory, we believe that the effects of reduced actual and potential movement outside the home on people's sense of self constitute an important field for further research.

Our study adds further evidence to the large literature about the adverse effects driving cessation can have on older people's wellbeing (e.g. Harrison and Ragland 2003; Davey 2007). In fact, we would suggest that driving cessation can constitutes a major life event for older people with potentially long-term or lasting consequences for older people's experience of wellbeing, much as losing one's spouse or job can (Lucas 2007), but it should be appreciated that driving cessation may not only affect a persons' (longer-term) life satisfaction or (shorter-term) happiness, but reach more deeply into her/his sense of self, as Robert's case suggested. Nonetheless, we emphasise that restricted physical mobility does not inevitably lead to decreased wellbeing as some studies of driving cessation seem to suggest (e.g. Marottoli et al. 1997, 2000). Our analysis has shown that reduced mobility in physical space can to some extent be compensated for by other dimensions of mobility. Participants redefined their own mobility in terms of electronic (use of TV, radio, phone, Internet and other information and communication technologies), imaginary (using memory) or mental mobilities. Physical ageing is thus accompanied by a shift in meaning which supports a positive self-image. At least two previous studies have made closely related points: Mollenkopf et al. (2004) argued that the negative effects of immobility on social contact can be offset partially by a self-perception of being in control over one's life and a strong 
motivation for being on the go, and Siren and Hakamies-Blomqvist (2009: 8) argued that 'the way [travel and mobility] contribute to wellbeing is more complex, modified by individual compensation strategies and resources, lifestyles, and personal meanings related to mobility, for example'. Thus, reduced mobility in physical space may entail lower levels of wellbeing, but this outcome is not inevitable.

Further, the link between mobilities and wellbeing via independence emerged very clearly from the analysis. Independence is, however, a complicated and contested notion in social gerontology (e.g. Secker et al. 2003; Fine and Glendinning 2005) and we suggest distinctions are required between independence, dependence and inter-dependence in relation to mobility and wellbeing. More specifically, based on the data analysis and drawing on Secker et al. (2003), we suggest that mobility contributes to wellbeing because it provides independence or a subjective experience of choice, social usefulness and autonomy. If, however, reduced mobility entails dependence - an unequal relationship of reliance on other people for assistance - wellbeing may be compromised, as illustrated by Robert's case and contributions of other focus group participants. On the other hand, relationships of inter-dependence (Urry 2007), which are experienced as more reciprocal, as with Doreen's 'coffee mornings, being with people', are valued more positively by the study participants. These relationships contribute to wellbeing and are enabled and enacted through mobilities.

Finally, one dimension of mobilities that this article has shown to be crucial to subjective wellbeing is mobility of the self. This result aligns with other studies in gerontology that emphasise the important role of the individual's predispositions for positive ageing and wellbeing (Levy et al. 2002; Seicol 2005; Bowling and Gabriel 2007). This study shows that mobility of the self not only drives continued mobility in physical space and a generally 
active lifestyle in later life, as Jane and Nancy made clear; it also contributes to a continued sense of wellbeing when physical mobility declines, as the examples of Hilda and Barbara evinced. It is for these particular reasons that we believe future studies of wellbeing in old age may benefit from adopting a holistic and relational conception of mobility.

\section{Acknowledgements}

This study was funded by the United Kingdom Economic and Social Research Council and Age Concern England, and carried out in collaboration with Age Concern Durham County. The authors thank the research participants for sharing their experiences and views.

\section{References}

Adler, G. and Rottunda, G. 2006. Older adults' perspectives on driving cessation. Journal of Aging Studies, 20, 3, 227-35.

Allen, J. 2008. Older People and Wellbeing. Institute for Public Policy Research, London. Available at http://www.ippr.org/publicationsandreports/publication.asp?id=620 [Accessed 29 March 2010].

Alsnih, R. and Hensher, D.A. 2003. The mobility and accessibility expectations of seniors in an aging population. Transportation Research A: Policy and Practice, 37, 10, 903-16.

Ayis, S.A., Bowling, A., Gooberman-Hill, R. and Ebrahim, S. 2007. The effect of definitions of activities of daily living on estimates of changing ability among older people.

International Journal of Rehabilitation Research, 30, 1, 39-46.

Banister, D. and Bowling, A. 2004. Quality of life for the elderly: the transport dimension. Transport Policy, 11, 2, 105-15.

Bowling, A. 2005. Ageing Well: Quality of Life in Old Age. Open University Press, Maidenhead, UK. 
Bowling, A. and Gabriel, Z. 2007. Lay theories of quality of life in older age. Ageing \& Society, 27, 6, 827-48.

Carlisle, S. and Hanlon, P. 2007. The complex territory of well-being: contestable evidence, contentious theories and speculative conclusions. Journal of Public Mental Health, 6, 1, 8-13.

Cutler, S.J. 1972. The availability of personal transportation, residential location, and life satisfaction. Journal of Gerontology, 27, 3, 383-89.

Cvitkovich, Y. and Wister, A. 2001. The importance of transportation and prioritization of environmental needs to sustain wellbeing among older adults. Environment and Behavior, 33, 6, 809-29.

Davey, J.A. 2007. Older people and transport: coping without a car. Ageing \& Society, 27, 1, 49-65.

Department of Health 2005. Independence, Well-being and Choice: Our Vision for the Future of Social Care for Adults in England. Social Care Green Paper, Stationery Office, London. Available online at http://www.dh.gov.uk/en/Publicationsandstatistics/Publications/PublicationsPolicyAnd Guidance/DH_4106477 [Accessed 29 March 2010].

Diener, E., Suh, E.M., Lucas, R.E. and Smith, H.L. 1999. Subjective well-being: three decades of progress. Psychological Bulletin, 125, 2, 276-302.

Fine, M. and Glendinning, C. 2005. Dependence, independence or inter-dependence? Revisiting the concepts of 'care' and 'dependence'. Ageing \& Society, 25, 4, 601-21. Fleuret, S. and Atkinson, S. 2007. Wellbeing, health and geography: a critical review and research agenda. New Zealand Geographer, 63, 2, 106-18.

Frello, B. 2008. Towards a discursive analytics of movement: on the making and unmaking of movement as an object of knowledge. Mobilities, 3, 1, 25-50. 
Föbker, S. and Grotz, R. 2006. Everyday mobility of elderly people in different urban settings: the example of the city of Bonn, Germany. Urban Studies, 43, 1, 99-118.

Gabriel, Z. and Bowling, A. 2004. Quality of life from the perspectives of older people. Ageing \& Society, 24, 5, 675-91.

George, L.K. 1981. Subjective well-being: conceptual and methodological issues. Annual Review of Gerontology and Geriatrics, 2, 345-82.

George, L.K. 2000. Well-being and sense of self: what we know and what we need to know. In Schaie, K.W. and Hendricks, J. (eds), The Evolution of the Aging Self: The Societal Impact of the Aging Process. Springer Publishing Company, New York, 1-35.

Gilroy, R. 2007. Taking a capabilities approach to evaluating supportive environments for older people. Applied Research in Quality of Life, 1, 3-4, 343-56.

Gilroy, R. 2008. Places that support human flourishing: lessons from later life. Planning Theory and Planning, 9, 2, 145-63.

Hanson, P. 1977. The activity patterns of elderly households. Geografiska Annaler, Series B: Human Geography, 59, 2, 109-24.

Harrison, A. and Ragland, D. 2003. Consequences of driving reduction or cessation for older adults. Transportation Research Record, 1843, 96-104.

Hildebrand, E.D. 2003. Dimensions in elderly travel behaviour: a simplified activity-based model using lifestyle clusters. Transportation, 30, 3, 285-306.

Iedi, H. and Muraki, Y. 1999. Can improved mobility raise the elderly's sense of fulfilment? Japan Railway and Transport Review, 20, 1, 14-21.

Kahn, R.L. and Juster, F.T. 2002. Well-being: concepts and measures. Journal of Social Issues, 58, 4, 627-44.

Kahneman, D. and Krueger, A.B. 2006. Developments in the measurement of subjective well-being. Journal of Economic Perspectives, 1, 20, 3-24. 
Kaiser, H.J. 2009. Mobility in old age: beyond the transportation perspective. Journal of Applied Gerontology, 28, 4, 411-29.

Katz, S. 1983. Assessing self-maintenance: activities of daily living, mobility, and instrumental activities of daily living. Journal of the American Geriatrics Society, $\mathbf{3 1}$, $12,721-7$.

Keyes, C.L.M., Shmotkin, D. and Ryff, C.D. 2002. Optimizing well-being: the empirical encounter of two traditions. Journal of Psychology and Social Psychology, 82, 6, 100722.

Kesby, M. 2000. Participatory diagramming: deploying qualitative methods through an action research epistemology. Area, 32, 4, 422-35.

Lawton, M.P. and Brody, E.M. 1969. Assessment of older people: self-maintaining and instrumental activities of daily living. The Gerontologist, 9, 3, 179-86.

Levy, B.R., Slade, M.D., Kunkel, S.R. and Kasl, S.V. 2002. Longevity increased by positive self-perceptions of aging. Journal of Personality and Social Psychology, 83, 2, 261-70.

Lowe, P. and Speakman, L. 2006. The Ageing Countryside: The Growing Older Population of Rural England. Age Concern England, London.

Lucas, R.E. 2007. Adaptation and the set-point model of subjective well-being: does happiness change after major life events? Current Directions in Psychological Science, 16, 2, 75-9.

Marottoli, R.A., Mendes de Leon, C.F., Glass, T.A., Williams, C.S., Cooney Jr, L.M., Berkman, L.F. and Tinetti, M.E. 1997. Driving cessation and increased depressive symptoms: prospective evidence from the New Haven EPESE. Journal of the American Geriatrics Society, 45, 2, 202-6. 
Marottoli, R.A., Medes de Leon, C.F., Glasse, T.A., Williams, C.S., Cooney Jr, L.M. and Berkman, L.F. 2000. Consequences of driving cessation: decreased out-of-home activity levels. Journal of Gerontology Series B: Social Sciences, 55, 6, S334-40.

Metz, D. 2000. Mobility of older people and their quality of life. Transport Policy, 7, 2, 14952.

Mokhtarian, P.L. and Salomon, I. 2001. How derived is the demand for travel? Some conceptual and measurement considerations. Transportation Research A, 35, 8, 695719.

Mollenkopf, H., Marcellini, F., Ruoppila, I., Széman, Z., Tacken, M. and Wahl, H.-W. 2004. Social and behavioural science perspectives on out-of-home mobility in later life: findings from the European project MOBILATE. European Journal of Ageing, 1, 1, 4553.

Mollenkopf, H., Marcellini, F., Ruoppila, I., Széman, Z. and Tacken, M. 2005. Enhancing Mobility in Later Life: Personal Coping, Environmental Resources and Technical Support. The Out-of-home Mobility of Older Adults in Urban and Rural Regions in Five European Countries. IOS Press, Amsterdam.

Mor, V., Murphy, J., Masterson-Allen S., Willey, C., Razmpour, A., Jackson, M.E., Greer, D. and Katz, S. 1989. Risk of functional decline among well elders. Journal of Clinical Epidemiology, 42, 9, 895-904.

Paez, A., Scott, D., Potoglou, D., Kanaroglou, P. and Newbold, B. 2007. Elderly mobility: demographic and spatial analysis of trip making in the Hamilton CMA, Canada. Urban Studies, 44, 1, 123-46.

Ragland, D.R., Satariano, W. and MacLoad, K.E. 2005. Driving cessation and increased depressive symptoms. Journal of Gerontology: Medical Sciences, 60A, 3, 399-403. 
Ryan, R.M. and Deci, E.L. 2001. On happiness and human potentials: a review of research on hedonic and eudemonic well-being. Annual Review of Psychology, 52, 1, 141-66.

Ryff, C.D. 1989a. Happiness is everything, or is it? Explorations of the meaning of psychological well-being. Journal of Personality and Social Psychology, 57, 6, 106981.

Ryff, C.D. 1989b. In the eye of the beholder: views of psychological well-being among middle-aged and older adults. Psychology and Aging, 4, 2, 195-210.

Ryff, C.D. 1995. Psychological well-being in adult life. Current Directions in Psychological Science, 4, 4, 99-104.

Schaie, K.W. and Pietrucha, M. 2000. Mobility and Transportation in the Elderly. Springer Publishing Company, New York.

Scheiner, J. 2006. Does the car make elderly people happy and mobile? Settlement structures, car availability and leisure mobility of the elderly. European Journal of Transport and Infrastructure Research, 6, 2, 151-72.

Secker, J., Hill, R., Villeneau, L. and Parkman, S. 2003. Promoting independence: but promoting what and how? Ageing \& Society, 23, 3, 375-91.

Seicol, S.R. 2005. A pastoral understanding of positive aging. In Moody, H.R. (ed.), Religion, Spirituality and Aging: a Social Work Perspective. Haworth Social Work Practice Press, Binghamton, New York, 293-302.

Sheller, M. and Urry, J. 2006. The new mobilities paradigm. Environment and Planning A, 38, 2, 207-26.

Siren, A. and Hakamies-Blomqvist, L. 2005. Sense and sensibility: a narrative study of older women's car driving. Transportation Research F: Traffic Psychology and Behaviour, 8, 3, 213-28. 
Siren, A. and Hakamies-Blomqvist, L. 2006. Does gendered driving create gendered mobility? Community-related mobility in Finnish women and men aged 65+. Transportation Research F: Traffic Psychology and Behaviour, 9, 5, 374-82.

Siren, A. and Hakamies-Blomqvist, L. 2009. Mobility and wellbeing in old age. Topics in Geriatric Rehabilitation, 25, 1, 3-11.

Smith, J., Borchelt, M., Maier, H. and Jopp, D. 200. Health and well-being in the young old and oldest old. Journal of Social Issues, 58, 4, 715-32.

Spinney, J.E.L., Scott, D.M. and Newbold, K.B. 2009. Transport mobility benefits and quality of life: a time-use perspective of elderly Canadians. Transport Policy, 16, 1, 111.

Scott, D.M., Newbold, K.B., Spinney, J.E.L., Mercado, R., Paez, A. and Kanaroglou, P.S. 2009. New insights into senior travel behavior: the Canadian experience. Growth and Change, 40, 1, 140-68.

Urry, J. 2006. Travelling times. European Journal of Communication, 21, 3, 357-72.

Urry, J. 2007. Mobilities. Polity, Cambridge.

Waldorf, B. 2003. Automobile reliance among the elderly: race and spatial context effects. Growth and Change, 34, 2, 175-201.

Wilhelmson, K., Andersson, C. Waern, M. and Allebeck, P. 2005. Elderly people's perspectives on quality of life. Ageing \& Society, 25, 4, 585-600.

Windsor, T.D., Anstey, K.J., Butterworth, P., Luszcz, M.A. and Andrews, G.R. 2007. The role of perceived control in explaining depressive symptoms associated with driving cessation in a longitudinal study. The Gerontologist, 47, 2, 215-23.

World Health Organization (WHO) 2002. Active Ageing; a Policy Framework. WHO, Geneva. Available online at 
http://whqlibdoc.who.int/hq/2002/WHO_NMH_NPH_02.8.pdf [Accessed 29 March 2010]. 
TABLE 1. The interactions between mobility and wellbeing for Jean

\begin{tabular}{|c|c|c|}
\hline $\begin{array}{l}\text { MOBILITY } \\
\text { dimensions }\end{array}$ & Interactions & $\begin{array}{l}\text { WELLBEING } \\
\text { dimensions }\end{array}$ \\
\hline Practices & $\begin{array}{c}\text { ARTHRITIS } \\
\text { Restricts engagement in mobile and stationary } \\
\text { practices, leading to (1) below }\end{array}$ & Physical health \\
\hline $\begin{array}{l}\text { Moving } \\
\text { through space }\end{array}$ & $\begin{array}{c}\text { Dependent on wheelchair. } \\
\text { Restrictions in accessibility, leading to (2) } \\
\text { below }\end{array}$ & $\begin{array}{l}\text { Autonomy and } \\
\text { independence }\end{array}$ \\
\hline \multirow[t]{3}{*}{ Disposition } & $\begin{array}{c}\text { Doesn't like to ask for help. } \\
\text { Considers herself a 'nuisance', leading to (3) } \\
\text { below }\end{array}$ & \multirow[t]{3}{*}{$\begin{array}{l}\text { Mental health and } \\
\text { emotional } \\
\text { wellbeing }\end{array}$} \\
\hline & (1) Loss of confidence & \\
\hline & $\begin{array}{l}\text { Fighting to maintain positive mental health, } \\
\text { leading to (4) below }\end{array}$ & \\
\hline $\begin{array}{l}\text { Attitudes to moving } \\
\text { through space and } \\
\text { practices }\end{array}$ & $\begin{array}{l}\text { Personal emphasis on independent practices. } \\
\text { (2) Avoidance of inaccessible village shops. } \\
\text { (3) Avoidance of social encounters, leading to } \\
\text { self-imposed mobility restrictions }\end{array}$ & Social relationships \\
\hline Imaginary mobility & $\begin{array}{l}\text { Memories of upsetting or difficult situations } \\
\text { as disabled person. } \\
\text { Fear of confrontational encounters } \\
\text { (4) Avoidance of difficult outings and social } \\
\text { encounters means that she can ignore } \\
\text { disability to an extent }\end{array}$ & \multirow[t]{3}{*}{$\begin{array}{l}\text { Continuity of the } \\
\text { self and identity }\end{array}$} \\
\hline & $\begin{array}{c}\text { Physical, mental and social disconnection } \\
\text { Leading to further restrictions in physical and } \\
\text { social activity and potential deterioration of } \\
\text { mental health }\end{array}$ & \\
\hline & $\Rightarrow$ RECLUSIVE & \\
\hline
\end{tabular}


TABLE 2. The dimensions of personal mobility

Dimension

Explication

Mobility practices These encompasses acts of moving between different locations at various temporal frequencies (from daily or weekly travel for shopping to occasional trips to visit relatives or for holidays), practices that accompany moving through physical space (even within a restricted area such as the dwelling), as well as practices to maintain or increase physical and mental fitness, such as exercise, gardening, doing crosswords and interacting with other people

Mobility of the self The general will or psychological disposition to connect with the world and with difference

Attitudes towards

Attitudes towards pursuing hobbies and personal interests or towards mobility practices the car. These attitudes can be thought of as dispositions towards specific sequences of acts in everyday life and are more concrete than the previous dimension of mobility of the self. These more concrete dispositions mediate between mobility of the self and mobility practices

Imaginary mobility Cognitive processes (memory and imagination) that recollect or construct events in other times (past or future) and other places.

Electronic mobility Electronic communication or information retrieval as a substitute for mobility or to supplement physical mobility, as with the Internet, telephone and television. 
TABLE 3. Conceptual relationships between mobility and wellbeing with individual factors of influence

\begin{tabular}{|c|c|c|}
\hline $\begin{array}{l}\text { MOBILITY } \\
\text { dimensions }\end{array}$ & $\begin{array}{l}\text { Individual factors that influence, and are } \\
\text { influenced by, mobility and wellbeing }\end{array}$ & $\begin{array}{l}\text { WELLBEING } \\
\text { dimensions }\end{array}$ \\
\hline Practices & $\begin{array}{l}\text { Level of activity; } \\
\text { capability }\end{array}$ & Physical health \\
\hline $\begin{array}{l}\text { Moving } \\
\text { through space }\end{array}$ & $\begin{array}{l}\text { Means of transport; } \\
\text { control }\end{array}$ & $\begin{array}{l}\text { Autonomy and } \\
\text { independence }\end{array}$ \\
\hline Disposition & $\begin{array}{c}\text { Personality; motivation; engaging with } \\
\text { difference; psychological coping } \\
\text { strategies }\end{array}$ & $\begin{array}{l}\text { Mental health and } \\
\text { emotional } \\
\text { wellbeing }\end{array}$ \\
\hline $\begin{array}{l}\text { Attitudes towards } \\
\text { moving and practices }\end{array}$ & $\begin{array}{l}\text { Attitudes to transport, local access; social } \\
\text { engagement; degree of inter-dependence; }\end{array}$ & Social relationships \\
\hline Imaginary mobility & $\begin{array}{l}\text { Previous experience; memories; future and } \\
\text { ageing }\end{array}$ & $\begin{array}{l}\text { Continuity of the } \\
\text { self and identity }\end{array}$ \\
\hline
\end{tabular}

